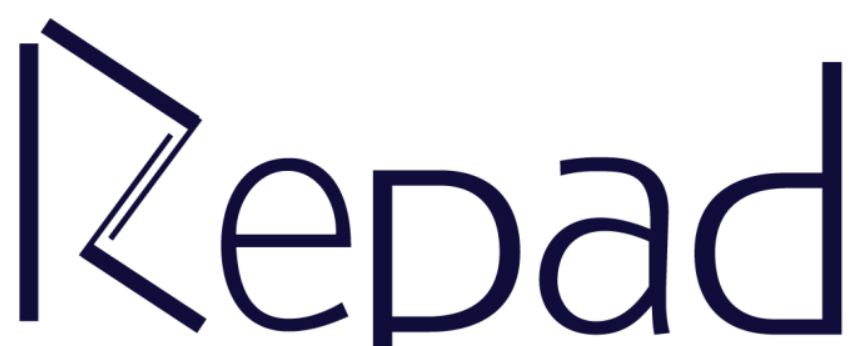

v. 4, n. 2, Maio-Agosto/2020

Revista Estudos e

Pesquisas em Administração 


\title{
REMUNERAÇÃO DE EXECUTIVOS: Uma análise da produção científica internacional de 2006 a 2015
}

Roberto Francisco de Souza robertofsouzajr@gmail.com

https://orcid.org/0000-0001-9776-9139

Universidade Estadual do Oeste do Paraná

Salvador- Bahia, Brasil

Ivan Rafael Defaveri

https://orcid.org/0000-0002-7385-6948

Universidade Estadual do Oeste do Paraná

Cascavél-Paraná, Brasil

Delci Grapegia Dal Vesco

https://orcid.org/0000-0002-0818-3142

Universidade Estadual do Oeste do Paraná

Cascavél-Paraná, Brasil

\section{Resumo}

Esta pesquisa aborda a produção cientifica sobre remuneração executiva no período de 2006 a 2015. Tem como objetivo investigar a produção científica permanente sobre remuneração de executivos, disponíveis na base de dados internacional Scopus. Para o estudo e para a interpretação dos dados, utilizou-se a análise de conteúdo fundamentada em Bardin. Foram analisados os títulos de 571 artigos, considerando o termo "executive compensation". Verificou-se que o tema é frequentemente discutido no cenário internacional. Há concentração de pesquisas em países desenvolvidos, destacando-se os EUA, UK, e em desenvolvimento, com destaque para a China. A literatura de governança corporativa é a mais recorrente nas pesquisas relacionadas à remuneração de executivos, seguida pela literatura de desempenho e teoria da agência. Predomina a metodologia quantitativa com o uso de técnicas estatísticas e modelagem econométrica.

Palavras-Chave: Remuneração de Executivos; Sistemas de Incentivo; Bibliometria.

\section{EXECUTIVE REMUNERATION: An analysis of international scientific production from 2005 to 2015}

\begin{abstract}
This research addresses the scientific production on executive remuneration from 2006 to 2015. It aims to investigate the permanent scientific production on executive remuneration, available in the international database Scopus. For the study and interpretation of data, content analysis based on Bardin was used. The titles of 571 articles were analyzed, considering the term "executive compensation". It was found that the theme is frequently discussed on the international stage. There is a concentration of research in developed countries, especially the USA, UK and developing China. The corporate governance literature is the most recurrent in surveys related to executive compensation, followed by performance literature and agency
\end{abstract}


theory. The quantitative methodology predominates with the use of statistical techniques and econometric modeling.

Keywords: Executive Compensation; Incentive Systems; Bibliometrics.

Submetido: $19 / 01 / 2020$

Nova Submissão: $08 / 05 / 2020$

Aceito: $15 / 05 / 2020$

Publicado: 31/05/2020

\section{INTRODUÇÃO}

O debate acerca da remuneração de executivos é um tema que vem ganhando cada vez mais destaque a partir da década de 1990, ao se levar em consideração que esses profissionais não se submetem as mesmas políicas de recursos humanos aplicadas aos demais funcionários de uma organização (OLIVA; ALBUQUERQUE, 2007).

A remuneração de executivos é um assunto algo complexo e controverso, principalmente ao se considerar como principal forma de análise dessas remunerações a teoria da agencia. De acordo com essa teoria, o acionista contrata um executivo, o agente, delegando a ele responsabilidades de tomada de decisão, com o intuito de receber vantagens nesse ciclo (CONYON, 2006).

Dessa forma, a remuneração paga aos Chief Executive Officer(CEOs) é uma forma de os acionistas conseguirem alinhar seus interesses ao do agente, para que, assim, esses convirjam em algo benéfico a ambos. No entanto, diversas pesquisas, realizadas, sobretudo nos Estados Unidos da América (EUA), indicam grandes índices de remuneração aos CEOs de grandes empresas desse país, levantando a questão do atendimento desses agentes aos interesses dos acionistas.

Segundo Krauter (2009), diversas pesquisas são realizadas, sobretudo nos EUA, buscando encontrar relação entre a remuneração paga aos executivos e desempenho das empresas por eles geridas, influenciadas, sobretudo, por casos onde de CEOs de grandes corporações terem divulgados rendimentos vultosos, enquanto as empresas geridas por eles apresentavam resultados pouco satisfatórios, o que demonstra pouco alinhamento entre os interesses dos executivos com as corporações que controlam.

Para que busquem essa conformidade com os objetivos da organização, os planos de remuneração devem ser compostos por quatro componentes básicos, sendo eles o salário base, bônus anual vinculado ao desempenho contábil ou outro indicador de desempenho acordado, e opções de ações (MURPHY, 1999). Além disso, também recebem incentivos financeiros, que incluem aumentos de salários, gratificações, benefícios e prerrogativas (automóveis, viagens de férias, títulos de clubes), incentivos psicológicos e sociais, que incluem possibilidades de promoção, aumentos de responsabilidade, aumento de autonomia, melhor localização e reconhecimento (troféus, participação em programas de excetivos) (ANTHONY; GOVINDARAJAN, 2006; MURPHY, 1999).

O estudo justifica-se pela importância do tema para os estudos organizacionais, bem como a limitação de informações sobre a remuneração dos agentes, onde se apontam necessários mais estudos sobre o assunto, abrindo caminho para novas pesquisas. A principal contribuição que se pretende neste estudo é apresentar as 
pesquisas que vêm sendo publicadas sobre remuneração de executivos e criar vínculo para futuras pesquisas.

Tomando-se como base o exposto, chega-se a seguinte questão de pesquisa: quais abordagens e teorias sobre remuneração de executivos são encontradas no contexto das pesquisas publicadas nos periódicos internacionais? Partindo dessa questão, a pesquisa toma como objetivo investigar as abordagens e teorias relacionadas à remuneração de executivos, publicadas em periódicos internacionais, disponíveis na base de dados Scopus.

\section{REFERENCIAL}

Nessa seção será discutida a literatura pertinente sobre o tema remuneração de executivos, sendo abordados os conceitos referentes aos termos remuneração $\mathrm{e}$ posteriormente, sistemas de incentivos.

\subsection{Remuneração}

A remuneração é um instrumento de administração de recursos humanos, que apresenta relevância no alinhamento dos agentes da empresa aos objetivos estratégicos desta (KRAUTER, 2013). Em vias gerais, Milkovich e Boudreau (2000) consideram a remuneração como um retorno financeiro, ou em forma de serviços ou benefícios, recebido pelos colaboradores de uma organização, em retribuição ao trabalho desprendido nesta. Hanashiro, Teixeira e Zacarelli (2008) indicam que o sentido de remuneração engloba outros fatores além do financeiro, de modo que existem modalidades distintas, que são resumidas por Krauter (2009) na Figura 1.

Figura 1. Modalidades de remuneração

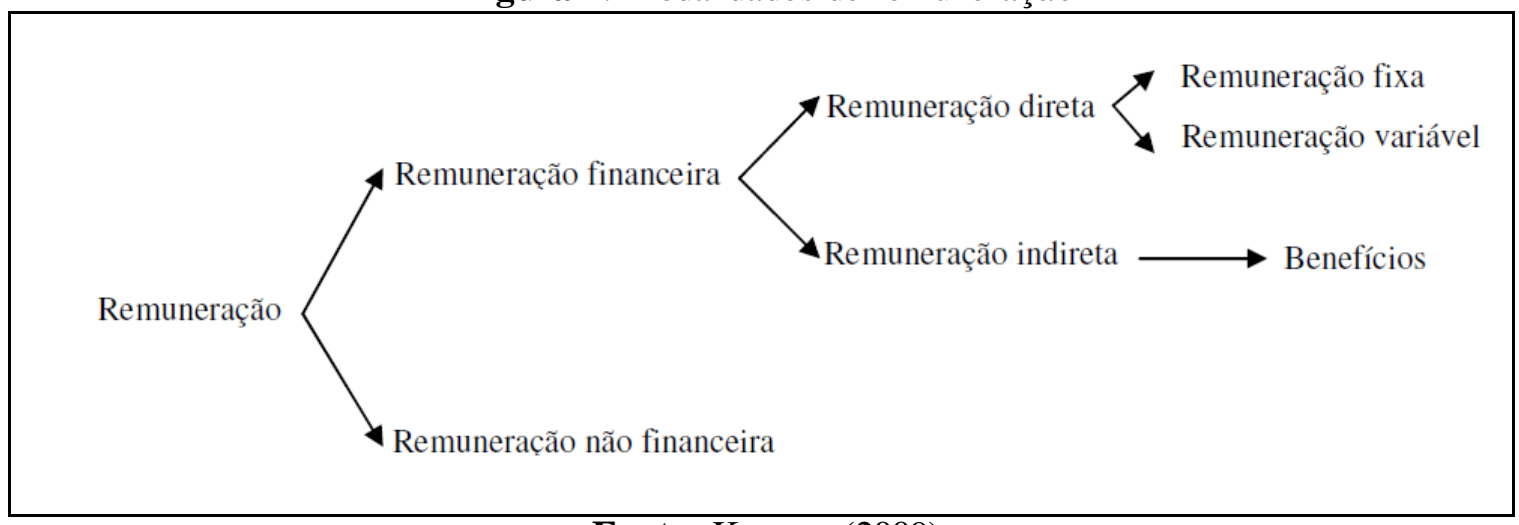

Fonte. Krauter (2009)

A remuneração pode ser direta ou indireta, sendo que a primeira refere-se a valores monetários recebidos em contraprestação ao trabalho realizado, e a segunda representa outros benefícios recebidos, como seguros, assistência odontológica (DUTRA, 2002).

Dentro da remuneração direta, a modalidade que mais se destaca no pagamento das contrapartidas a executivos de grandes empresas é a remuneração variável, que é colocada por Silva e Beuren (2015) como uma forma de remuneração em que o montante a ser recompensado ao CEO é determinado por critérios, como produtividade 
ou resultados. A remuneração variável pode ser paga por meio de diversas modalidades, sendo que Xavier et al. (1999) colocam que os modelos mais utilizados no Brasil são os bônus, gratificações, comissões, incentivos, participação nos lucros e resultados e participação acionária.

A remuneração de executivos na modalidade variável toma como base a Teoria da Agência, que indica que os acionistas transferem a responsabilidade em gerenciar a organização a um agente, o qual irá gerir a empresa mantendo o alinhamento de interesses dos acionistas, ou seja, em consonância de seus objetivos pessoais com os da organização (MURPHY, 1999).

Um fator determinante na remuneração de executivos é a delimitação de um plano de remuneração. A determinação de qual a modalidade de recompensas será utilizada para recompensar o CEO por seu trabalho. Krauter (2013) coloca que a base de uma política de remuneração está na determinação de como o executivo será recompensado. Dentro dessas formas de compensação, a autora cita a remuneração fixa, bônus a partir do desempenho, geralmente medido pelo lucro, bem como outras formas, entre elas opções de ações, revisões de salário, e incentivos (JENSEN; MURPHY, 1990).

\subsection{Sistemas de Incentivos}

Segundo Barkema e Gomez-Mejla (1998), os determinantes da remuneração dos gestores podem ser relacionados com: o desempenho; a dimensão da empresa; as características individuais; a estratégia da empresa; a dimensão e o crescimento do mercado.

Para Rodrigues (2014), os Sistemas de Incentivos são utilizados como forma de premiar os funcionários pelo seu desempenho, com o objetivo de motivá-los a desempenharem as suas funções de acordo com os interesses dos acionistas. Bouwens e Lent (2006) afirmam que um SI tem a capacidade de selecionar melhores funcionários, contudo pode não ser suficiente para obter um melhor desempenho empresarial. A Figura 2 mostra uma síntese dos sistemas de incentivo.

Figura 2. Sistemas de Incentivo.

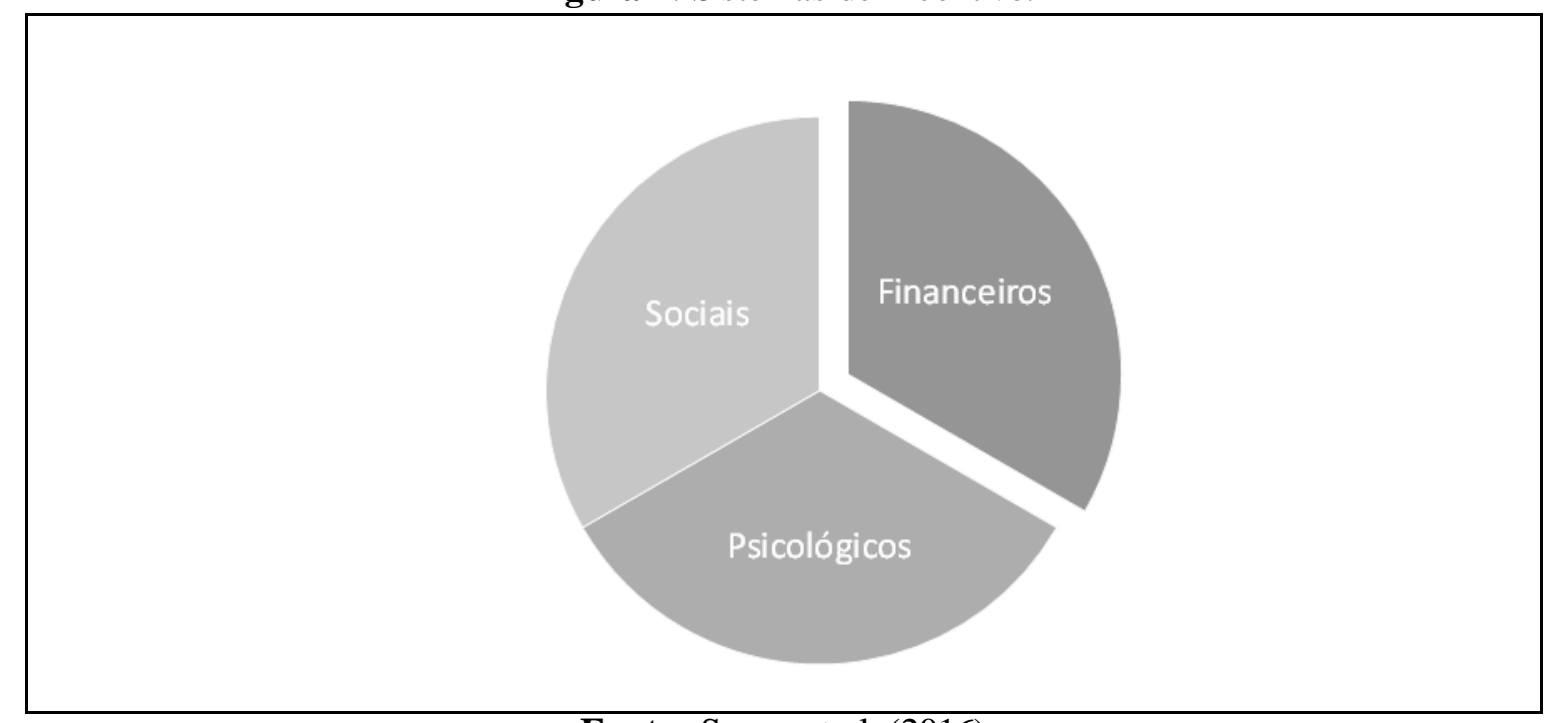

Fonte. Souza et al. (2016) 
Conforme indicado na Figura 2, para Anthony e Govindarajan (2006), os incentivos financeiros incluem aumentos de salários, gratificações, benéficos e prerrogativas (automóveis, viagens de férias, títulos de clubes), os incentivos psicológicos e sociais incluem possibilidades de promoção, aumentos de responsabilidade, aumento de autonomia, melhor localização e reconhecimento (troféus, participação em programas de executivos). Adicionalmente a esses três tipos, também a Literatura indica que os incentivos podem ser políticos (Status; poder, etc.).

Para Anthony e Govindarajan (2006), os planos de remuneração por incentivos podem ser divididos em (1) planos de incentivos à curto prazo, os quais se baseiam no desempenho do ano em curso, e (2) planos de incentivos à longo prazo, os quais se fundamentam no desempenho à longo prazo, sendo que estes consideram, geralmente, as cotações das ações da empresa nas bolsas. Um executivo pode ganhar uma gratificação sob os dois planos e as gratificações sob os planos à curto prazo são pagas, geralmente em dinheiro. As gratificações sob longo prazo são concedidas, geralmente, na modalidade de stock options.

\subsection{Leis da Bibliometria}

Pritchard (1969) é apontado como o proponente da expressão bibliometria em substituição ao termo "bibliografia estatística", apresentado inicialmente em 1922 por Edward Wyndham Hulme Pritchard (1969, p. 348) define a bibliometria como "[...] a aplicação da matemática e métodos estatísticos para livros e outros meios de comunicação". Para Macias-Chapula (1998, p. 134), “[...] a bibliometria é o estudo dos aspectos quantitativos da produção, disseminação e uso da informação registrada". Dessa forma essas definições posicionam a bibliometria como um estudo quantitativo que objetiva identificar características comuns entre os artigos científicos (MACHADO JUNIOR et al., 2016).

De acordo com Machado Junior et al. (2016), estudos que analisam estatisticamente características de publicações (autores, palavras-chave, entre outras) buscam quantificar, descrever e prognosticar o processo de comunicação escrita. Os estudos de frequência da comunicação, escrita ao longo do tempo, identificaram modelos de comportamento que se estabeleceram em padrões de análise de dados. Estes padrões se instituíram em princípios de comportamento, a saber: Lei de Lotka, Lei de Brandford, Lei e Zipf, entre outros. Pode-se dizer que a finalidade das pesquisas bibliométricas é colocar o pesquisador em contato com o que já foi produzido anteriormente a respeito do tema de pesquisa de interesse.

A Lei de Lotka (1926) ou Lei do Quadrado Inverso propõe que um número restrito de pesquisadores produz muito em determinada área de conhecimento, enquanto um grande volume de pesquisadores produz pouco. Em seu artigo The frequency distribution of scientific productivity, Lotka estudou os autores presentes no Chemical Abstracts, entre 1909 e 1916, e identificou que grande parte da produção científica é produzida por poucos autores. A produção deste número reduzido de autores se iguala em quantidade ao desempenho de muitos autores que possuem baixo volume de publicação. A representação deste princípio pode ser expressa matematicamente como o número de autores que publica $\mathrm{n}$ artigos (n é igual à quantidade de artigos) é igual a $1 / \mathrm{n} 2$ dos autores que publicam somente um artigo (MACHADO JUNIOR et al., 2016; SILVA, MARTINS, HEIN, 2018). 
Machado Junior et al. (2016) exemplificam a lógica matemática de Lotka da seguinte forma, "em determinada área de conhecimento a quantidade de autores que publicam dois artigos é igual a $1 / 4$ do número de autores que publicam um artigo. Para os autores que publicam três artigos correspondem a 1/9 dos que produziram somente um artigo".

A Lei de Bradford ou Lei da Dispersão, que incide sobre conjunto de periódicos, surgiu de pesquisas médicas conduzidas por Hill Bradford e outros médicos do conselho de pesquisas médicas americanas (BOGAERT; ROUSSEAU; VAN HECKE, 2000). Com o objetivo de descobrir a extensão na qual artigos de um assunto científico específico apareciam em periódicos destinados a outros assuntos, estudando a distribuição dos artigos em termos de variáveis de proximidade ou de afastamento, Bradford realiza uma série de estudos que culminam, em 1934, com a formulação da lei da dispersão (ARAÚJO, 2006).

Conforme Machado Junior et al. (2016), Bradford identificou a extensão de publicação de artigos científicos de um assunto específico, em revistas especializadas daquele tema. Os dados coletados mostraram a existência de um pequeno núcleo de periódicos que aborda $\mathrm{o}$ assunto de maneira mais extensiva, e uma vasta região periférica dividida em zonas. Nessas zonas observa-se o aumento do número de periódicos que reduzem a produtividade de publicação de artigos do respectivo assunto.

A Lei de Zipf ou Lei do Mínimo Esforço consiste em medir a frequência do aparecimento das palavras em vários textos, gerando uma lista ordenada de termos de uma determinada disciplina ou assunto. De acordo com Bardin (2011), a Lei de Zipf observa a frequência em que aparecem determinadas palavras ou palavras-chave em um texto. Formando uma classificação, a primeira palavra mais citada no texto, a segunda, a terceira e assim por diante. Sua utilidade reside em estabelecer, a partir da classificação, o assunto abordado nos textos analisados (SILVA et al., 2018).

$\mathrm{Na}$ Figura 3, Guedes e Borschiver (2005) apresentam as principais leis da Bibliometria, seus focos de estudo e suas relações com os sistemas de comunicação e de informação científica e tecnológica.

Figura 3. Leis da Bibliometria

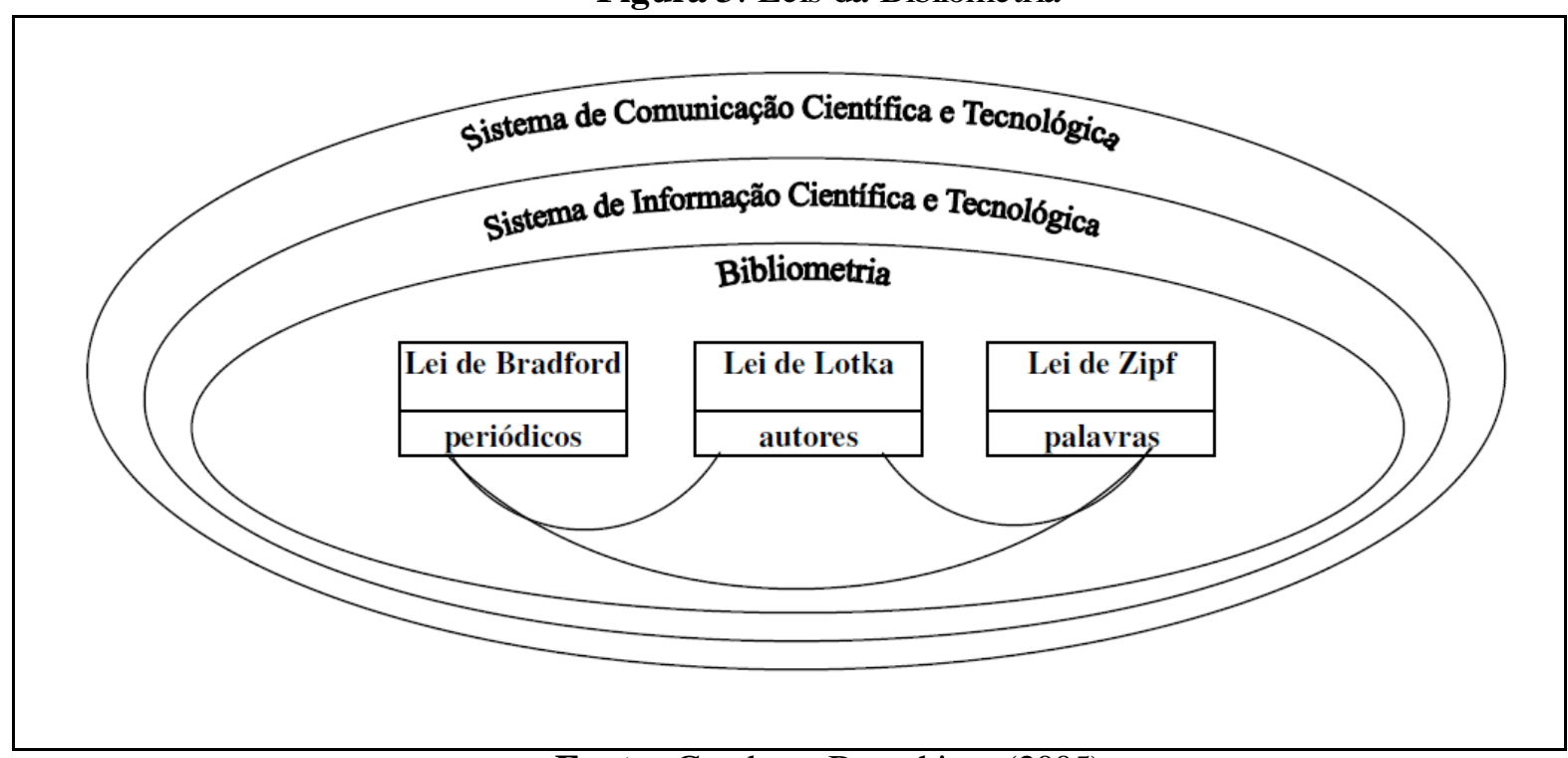

Fonte. Guedes e Borschiver (2005) 
Para Acedo e Casillas (2005), a Lei de Bradford mensura o nível de relevância dos periódicos sobre determinada área. Já a Lei de Lotka descreve a produtividade e as citações de autores por meio de um modelo de distribuição de tamanho-frequência, em um conjunto de pesquisas, evidenciando aspectos de coautoria (RIBEIRO; TAVARES; COSTA, 2016). E a Lei de Zipf calcula a quantidade de ocorrências das palavras em vários textos, gerando uma lista de terminações de determinado assunto, sendo utilizada para observar qual tema científico é tratado nos trabalhos (EGGHE, 2005). Dessa forma, segue-se para a definição metodológica do estudo.

\section{PROCEDIMENTOS METODOLÓGICOS}

Em resposta a problematização apresentada, o objetivo da pesquisa, enquadra-se em uma pesquisa descritiva, foi realizado levantamento bibliográfico no intuito de colher conhecimento prévio, conhecer a produção já existente e buscar pesquisas que fundamentassem a classificação a ser utilizada no estudo, com abordagem qualitativa.

O universo do estudo consistiu-se por consulta efetuada na base de dados internacional Scopus, utilizando as palavras-chave: "executive compensation". Inicialmente, por meio de busca avançada, foram identificados 910 artigos relacionados a remuneração executiva, compreendendo o período de 2006 a 2015.

Para análise e interpretação dos dados foi utilizada a análise de conteúdo, segundo Bardin (1991, p. 42), resume-se em um conjunto de técnicas de análise das comunicações, visando obter, por procedimentos, sistemáticos e objetivos de descrição do conteúdo das mensagens, indicadores quantitativos ou não, que permitam a inferência de conhecimentos relativos ás condições de produção/recepção (variáveis inferidas) destas mensagens.

Assim, o processo da análise de conteúdo, fundamentou-se na análise de todos os títulos, resumos e palavras chave dos trabalhos com categorização, considerando-se a presença ou ausência do termo "executive compensation" nos artigos pesquisados, restringindo-se ás subáreas, Business, Management and Accounting (632) e Decision Sciences (27). Foram excluídos 88 artigos, por não possuírem abordagens referentes ao objetivo da pesquisa.

Partindo do método apresentado, puderam-se inferir os seguintes dados, analisados com o intuito de atender aos objetivos da pesquisa.

\section{ANALISE E DISCUSSÃO DOS DADOS}

Esta seção expõe a análise de publicações referente a remuneração executivos na base de dados internacional Scopus, no período de 2006 a 2015. Conduziu-se a análise e apresentação dos resultados pela seguinte ordem: distribuição da produção científica ao longo do tempo; produtividade dos periódicos (Lei de Bradford); produtividade dos autores (Lei de Lotka); frequência de palavras (Lei de Zipf).

As informações contidas na Figura 4 revelam que as publicações de trabalhos sobre remuneração executiva aumentaram gradativamente entre os anos de 2006 e 2009, no entanto houve um crescimento expressivo de $62 \%$ na produção de artigos no período de 2009 a 2013, o qual no ano de 2011 apresentou 72 publicações, seguido de 71 no ano de 2010. No entanto esse crescimento talvez seja explicado pelo interesse da academia em investigar a remuneração de executivos após os grandes escândalos em função de executivos, sobretudo norte-americanos que por algum tempo possuíram altos salários 
ao mesmo tempo em que as empresas sob sua administração apresentavam resultados negativos.

Figura 4. Comparativo entre artigos publicados relacionado com a remuneração executiva

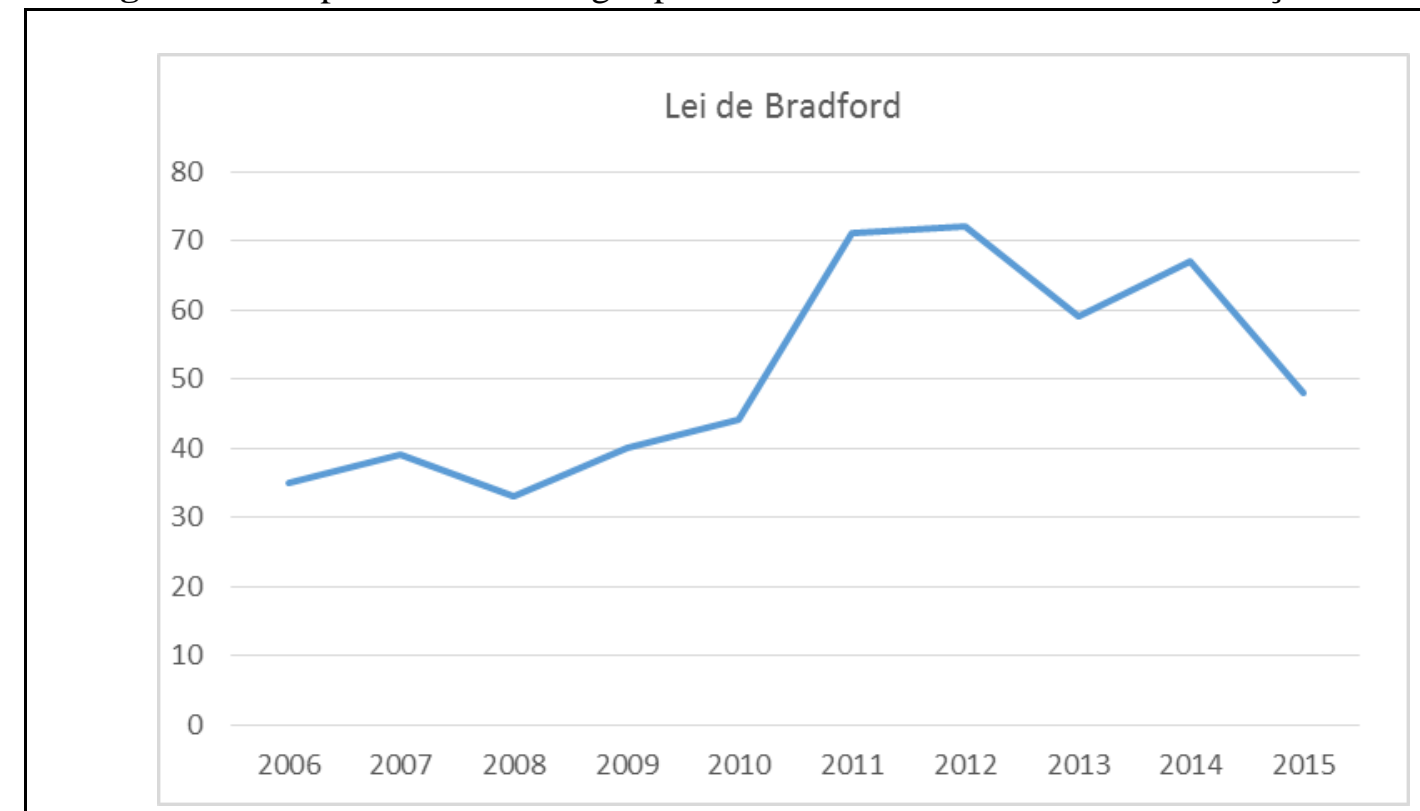

Fonte. Dados da pesquisa

Também, pode-se observar a existência de duas correntes de pesquisas sobre remuneração executiva, uma voltada para os Estados Unidos e outra para a Europa destacando o Reino Unido. Contudo houve significativa redução no ano de 2013, permanecendo até 2015.

De acordo com a Tabela 1, a condição de maior concentração de trabalhos que tratam do tema remuneração executiva concentra-se em três periódicos sendo que o Journal of Financial Economics, que liderou em 5 dos 10 anos pesquisados, apresentando um expressivo número de artigos relacionados ao tema pesquisado, é, portanto, o periódico de maior impacto quando o assunto é remuneração.

Tabela 1. Citações por periódico

\begin{tabular}{l|c|c}
\hline \multicolumn{1}{c|}{ Periódico } & Ano & \% \\
\hline Journal of Business Ethics & 2006 & 0,21 \\
\hline Review of Accounting Studies & 2007 & 0,24 \\
\hline Journal of Financial Economics & 2008 & 5,12 \\
\hline Journal of Financial Economics & 2009 & 2,76 \\
\hline Review of Financial Studies & 2010 & 2,61 \\
\hline Journal of Financial Economics & 2011 & 3,83 \\
\hline Journal of Corporate Finance & 2011 & 3,83 \\
\hline Journal of Financial Economics & 2012 & 1,76 \\
\hline Journal of Financial Economics & 2013 & 2,12 \\
\hline Journal of Corporate Finance & 2014 & 0,51 \\
\hline Management Science & 2014 & 0,51 \\
\hline Journal of Management & 2015 & 0,60 \\
\hline
\end{tabular}

Fonte. Dados da Pesquisa 
$\mathrm{Na}$ segunda colocação o Journal of Corporate Finance, aparece em 2 anos do período pesquisado, na terceira colocação, embora com um número menor de artigos publicados, o Review of Financial Studies, ressalta-se que outros periódicos também apresentaram elevado número de citações, o Journal of Management, o Management Science e o Journal of Business Ethics.

Essas informações permitem aceitar a Lei de Bradford, mostrando que, no tema de remuneração de executivos, um pequeno número de periódicos concentra a maior parte da produção, tendo maior impacto nas pesquisas sobre a área.

$\mathrm{Na}$ Tabela 2, listam-se os autores mais citados ou que mais pesquisaram sobre remuneração executiva. Os dados mostram que Armstrong, Chris S., é o autor com a maior produtividade no período pesquisado, liderando em 3 anos consecutivos. $\mathrm{Na}$ sequência Frydman, C., possui alta produtividade, sendo o mais expressivo pesquisador norte americano e ao mesmo tempo um dos maiores nomes se tratando de pesquisas relacionadas à temática remuneração executiva.

Tabela 2. Produtividade dos autores (Lei de Lotka)

\begin{tabular}{l|c|c}
\hline \multicolumn{1}{c|c}{ Autores } & Ano & \% \\
\hline Pukthuanthong, K., & 2007 & 0,17 \\
\hline Bizjak, J.M., & 2008 & 2,4 \\
\hline Berrone, P. & 2009 & 3,69 \\
\hline Frydman, C. & 2010 & 2,61 \\
\hline Conyon, Martin J. & 2011 & 1,67 \\
\hline Armstrong, Chris S. & 2012 & 1,46 \\
\hline Armstrong, Chris S. & 2013 & 0,34 \\
\hline Armstrong, Chris S. & 2014 & 0,81 \\
\hline Anantharaman, Divya & 2015 & 0,36 \\
\hline
\end{tabular}

$\mathrm{Na}$ terceira colocação, porém não menos importante, Conyon, também sendo um dos principais pesquisadores sobre remuneração no mundo e o mais conceituado na Europa. Destaca-se aqui a aceitação da Lei de Lotka, indicando que um pequeno número de pesquisadores tem produção consideravelmente superior a um grande número de outros pesquisadores, indicando maior representatividade no estudo da área.

Tabela 3. Instituições de Ensino mais citadas

\begin{tabular}{l|c|c}
\hline \multicolumn{1}{c|}{ IES } & Ano & \% \\
\hline San Diego State University, CA, United States & 2007 & 0,17 \\
\hline $\begin{array}{l}\text { The Wharton School, University of Pennsylvania, Philadelphia, United } \\
\text { States }\end{array}$ & 2008 & 2,36 \\
\hline IESE Business School, Spain & 2009 & 3,68 \\
\hline $\begin{array}{l}\text { Krannert School of Management, Purdue University, West Lafayette, } \\
\text { United States }\end{array}$ & 2010 & 2,76 \\
\hline Harvard Law School, Cambridge, United States & 2011 & 1,89 \\
\hline University of Pennsylvania, Wharton School, Philadelphia, United States & 2012 & 1,46 \\
\hline University of Pennsylvania, Wharton School, Philadelphia, United States & 2013 & 0,81 \\
\hline Temple University, Fox School of Business, Philadelphia, United States & 2014 & 0,17 \\
\hline University of St. Gallen, School of Management, United States & 2015 & 0,43 \\
\hline
\end{tabular}

Fonte. Dados da pesquisa 
$\mathrm{Na}$ Tabela 3, apresentam-se as instituições que mais apareceram nos periódicos analisados, embora de maneira fragmentada, ou seja, variando de acordo com o período pesquisado, as instituições de ensino norte americanas lideram as pesquisas sobre remuneração executiva, ano após ano. A University of Pennsylvania, Wharton School, Philadelphia, United States, lidera o número de citações no período analisado.

Seguida pelo IESE Business School, Spain, sendo o periódico europeu mais citado em 2009. No entanto observa-se a prevalência de instituições de ensino norte americana, e concentração de instituições no estado da Philadelphia. Krannert School of Management, Purdue University, West Lafayette, United States, Harvard Law School, Cambridge, United States.

Observa-se, na Figura 5, que as palavras mais destacadas são Governança, Desempenho, Agência, Gerenciamento, Risco, Executivo chief, Opções, Social, Equidade, Incentivo, Contabilidade, entre outros. A ocorrência frequente de tais termos sugere que, que a maioria dos artigos aborde diretamente o tema remuneração executiva, relacionado a teorias de diversas áreas como, finanças, economia, contabilidade, administração, psicologia, medicina e marketing. No entanto observa-se forte mudança no paradigma das pesquisas sobre remuneração, a base teórica mais utilizada está aos poucos deixando de ser a teoria da agência que trata especificamente dos conflitos entre o principal e o agente, dando espaço para outras teorias, sobretudo a teoria de governança com o surgimento da Lei SOX no início dos anos 2000, momento que o mundo atentou-se para os altos salários percebidos pelos executivos mesmo em situações que as empresas apresentavam resultados negativos.

Figura 5. Frequência de palavras Lei de Zipf

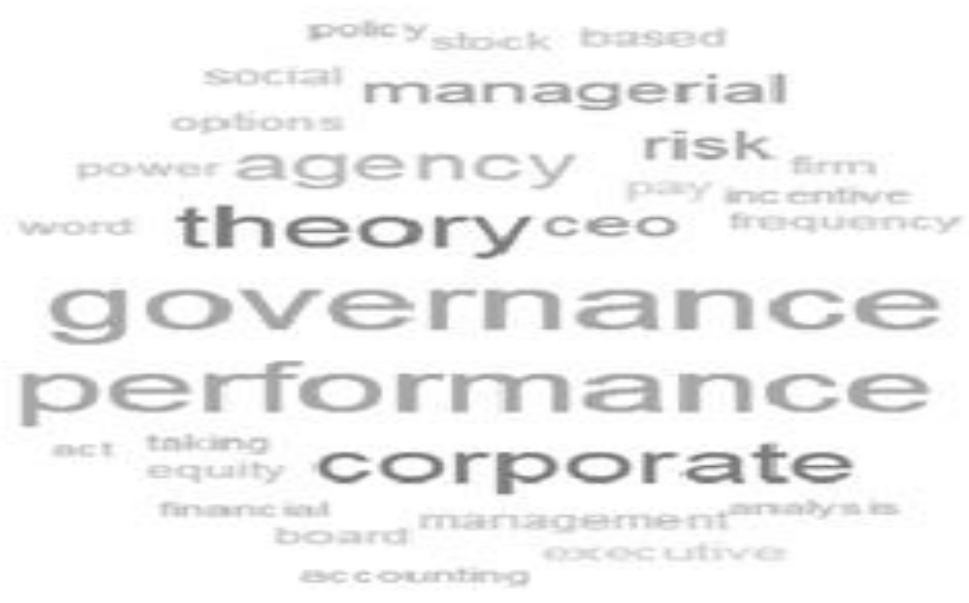

Fonte. Dados da pesquisa

Não obstante outras teorias emergiram como é o caso da Literatura de Desempenho geralmente relacionada aos vários tipos de remuneração, levantando indagações sobre qual é o tipo de remuneração mais adequado, qual vai alinhar melhor os objetivos da empresa aos do CEO os Planos de bônus anual, as Opção de ações, Outras Formas de Compensação de (MURPHY, 1999). Mas será que a alta 
remuneração pode resolver possíveis desvios de conduta do CEO ou ainda garantir que a organização terá resultados positivos?

A Literatura de Desempenho também vem sendo amplamente utilizada em pesquisa com a temática remuneração, sobre tudo para relacionando o desempenho do CEO influenciado pela remuneração o que acaba por remeter a outra literatura emergida na pesquisa, a de Gerenciamento de Resultado, que estuda a manipulação de resultado pelo CEO para galgar melhores salários em determinado período. Ainda emerge da pesquisa a literatura sobre o Chieff Executive Officer, que pesquisa os efeitos da remuneração em suas ações e comportamentos do CEO. Por fim cabe destacar a ausência de estudos que abordassem os incentivos sejam financeiros ou não financeiros baseados em (ANTHONY; GOVINDARAJAN, 2006).

No entanto, as palavras mais utilizadas se referem às teorias relacionadas à remuneração executiva, seja para as formas de remuneração, divulgação e desempenho. $\mathrm{Na}$ Figura 6, apresentam-se as principais abordagens teóricas relacionadas às pesquisas sobre remuneração executiva.

Figura 6. Abordagens Teóricas versus Remuneração Executiva

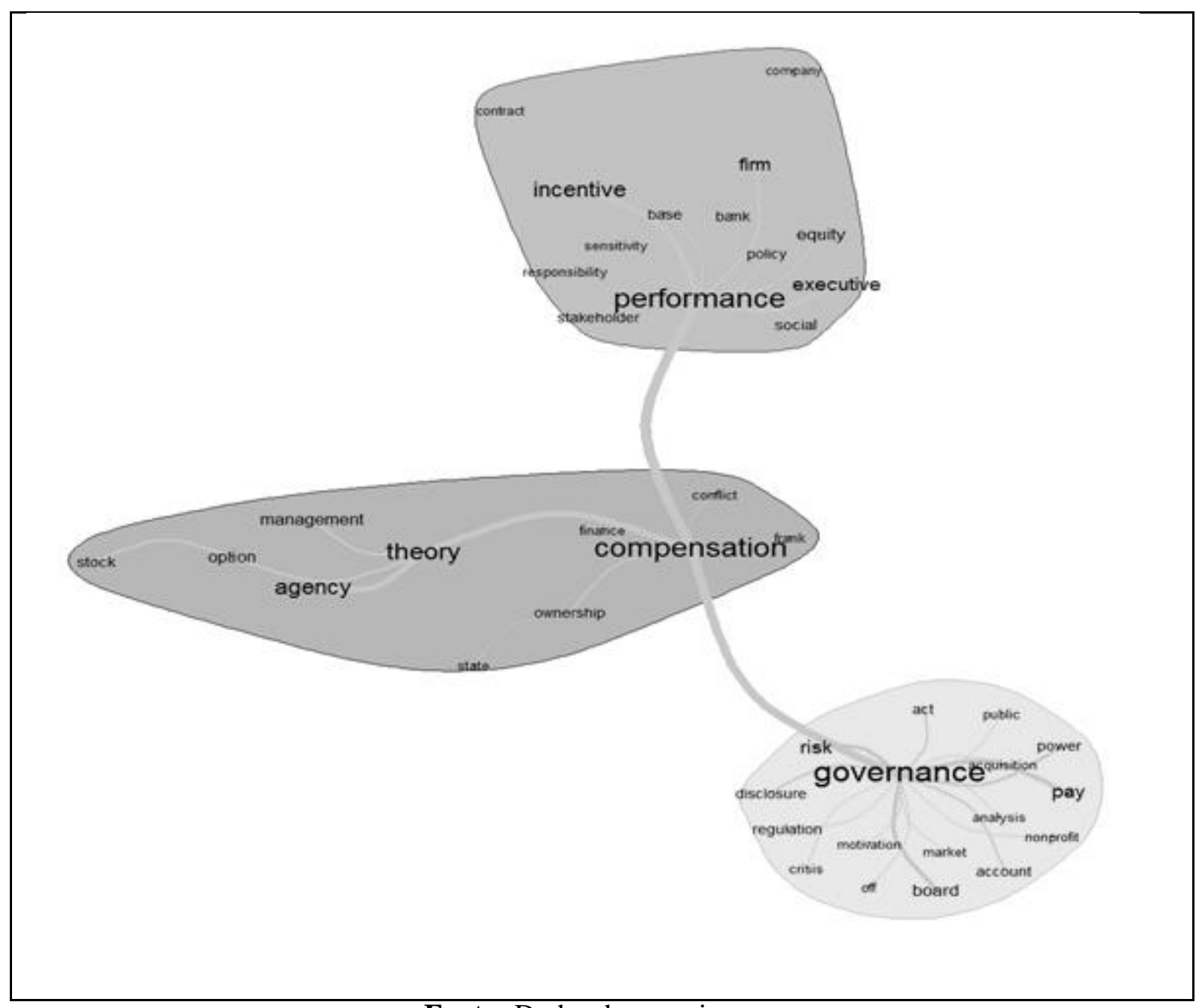

Fonte. Dados da pesquisa 
Diversas abordagens teóricas emergem da pesquisa relacionadas remuneração. A teoria da Agência, por muito anos, foi a mais recorrente, por discutir e propor soluções a partir dos tipos de remunerações existentes para solucionar os problemas de agência, ou seja, alinhar interesses entre o principal e o agente, acionista (dono) e o gestor (ceo). Por muitos anos, acadêmicos, políticos e meios de comunicação têm chamado a atenção sobre a temática remuneração, alertando sobre os elevados níveis de remuneração concedida aos diretores executivos nos Estados Unidos da América - EUA, e questionando se eles estão de acordo com os interesses dos acionistas (CONYON, 2006).

Mas também aspectos não financeiros da remuneração como é o caso dos incentivos financeiros e não financeiros. Conforme Jensen e Murphy (1990), os pacotes de remuneração geralmente são compostos das diferentes formas de compensação, a remuneração fixa, bônus a partir do desempenho, geralmente medido pelo lucro, bem como outras formas, entre elas opções de ações, revisões de salário, e incentivos. Conforme Conyon (2006), os incentivos financeiros são os de primeira ordem, pois motivam os gerentes a trabalharem em função de aumentar o preço das ações, e são os mais reportados nos estudos sobre remuneração. Os incentivos não financeiros, de segunda ordem, apesar de fazerem parte da remuneração dos gerentes, na literatura são reportados aos funcionários que estão abaixo do nível gerencial. Mesmo assim esses pacotes de remuneração parecem não garantir boa conduta ou ainda resultados operacionais positivos as organizações, dados a vários escândalos que deram origem a Lei Sarbanes-Oxley.

Assim, a literatura de governança corporativa ganhou espaço na academia, talvez o principal motivo seja a quebra de grandes corporações norte americanas por motivos de fraudes e corrupção. Geralmente relaciona seus princípios básicos; transparência, equidade, prestação de contas e responsabilidade corporativa ao comportamento e conduta do CEO, mas sob a influência da remuneração. Mas cabe destacar que a governança implica na redução de riscos como fraudes, corrupção ou ainda distorções nos relatórios contábil-financeiros, uma vez que todos os responsáveis pela alta administração poderão também responder por seus atos juntamente com a equipe técnica e operacional, o que remete a literatura de desempenho também muito presente nesta pesquisa.

A literatura de desempenho tem questionado a influência da remuneração sobre o desempenho do CEO em gerar resultados positivos. Normalmente são utilizados indicadores de rentabilidade para medir desempenho como; Retorno sobre o Ativo (ROA), Retorno sobre o Patrimônio (ROE), Tamanho da empresa (TAM), Market to Book (MB), Liquidez Geral e sobre a Remuneração dos diretores executivos (DEGENHART, MARTINS, HEIN, 2017; FORTI et al., 2018). Além disso, auxilia o entendimento dos valores pagos aos diretores executivos, demonstrando que o desempenho das empresas reflete na remuneração dos diretores executivos, fazendo com que estes atuem na empresa com vistas a elevar os resultados econômicofinanceiros (DEGENHART; MARTINS; HEIN, 2017). No entanto os incentivos financeiros e não financeiros também exercem influência no desempenho do CEO o que também poderá refletir no desempenho de empresas seja positivo ou negativamente (MURPHY, 1985; VLACHOS, 2009). 


\section{CONSIDERAÇÕES FINAIS}

Este artigo busca contribuir para o conhecimento da produção cientifica sobre a temática de remuneração e incentivos concedidos aos executivos CEOs ou, seja em países desenvolvidos ou em desenvolvimento. Para análise e interpretação dos dados foi utilizada a análise de conteúdo, segundo Bardin (1991). Foram analisados 571 artigos, respeitando as leis da Bibliometria, produtividade dos periódicos (Lei de Bradford); produtividade dos autores (Lei de Lotka); frequência de palavras (Lei de Zipf).

As publicações de trabalhos sobre remuneração executiva aumentaram gradativamente entre os anos de 2006 e 2009, houve um crescimento expressivo de $62 \%$ na produção de artigos no período de 2009 a 2013, o qual no ano de 2011 apresentou 72 publicações, seguido de 71 no ano de 2010. Contudo houve significativa redução no ano de 2013, permanecendo até 2015.

O Journal of Financial Economics, que liderou em 5 dos 10 anos pesquisados, apresentando um expressivo número de artigo relacionado ao tema pesquisado, é portanto o periódico de maior impacto. Os dados mostram que Armstrong, Chris S. esteve presente em grande parte do período pesquisado, liderando a produtividade em 3 anos consecutivos. As instituições de ensino norte americanas, de longe lideram as pesquisas sobre remuneração executiva, ano após ano. A University of Pennsylvania, Wharton School, Philadelphia, United States, foi a instituição que apareceu em quase todos os anos analisados.

Observa-se que a governança corporativa é a teoria mais recorrente nos títulos, resumos e palavras chaves dos artigos pesquisados. Seguida pela literatura desempenho, seja econômico, financeiro, contábil ou social. A teoria da Agência, também é muito recorrente ao tema, pois ela do suporte para a segregação de direitos e deveres entre principal e agente e os custos de agência, sendo em alguns casos utilizada concomitantemente com a governança corporativa. O Gerenciamento de resultado embora não seja muito expressivo aparece nos artigos pesquisados, seguido por Stakeholders, Teoria do Prospecto, Shareholders, Finanças comportamentais, Teoria dos Contratos, Divulgação Voluntária, Teoria da Equidade, e outras.

Quanto ao método observa-se que em quase a totalidade do universo pesquisado a abordagem metodológica quantitativa é a mais recorrente bem como os testes estatísticos e a modelagem econométrica, diferenciando uma ou outra variável explicativa nos modelos empíricos analisados. Ainda, Nota-se a concentração de pesquisas seja no continente americano ou do outro lado do atlântico, em destaque os EUA, e, o Reino Unido na Europa. Embora pouco expressivo, os países em desenvolvimento mais especificamente os que compõem o Brics - Brasil, Rússia, Índia, China e África do Sul, também aparecem no cenário internacional, destacando-se a China, devido ao desenvolvimento recente de seu mercado de capitais.

Conclui-se que o tema é bem explorado no cenário internacional, existe concentração de pesquisas em países desenvolvidos, destacando-se os EUA, UK e em desenvolvimento a ascensão da China. A literatura de governança corporativa é a mais recorrente nas pesquisas relacionadas a remuneração de executivos, seguida pela literatura de desempenho e teoria da agencia. Predomina a metodologia quantitativa com o uso de técnicas estatísticas e modelagem econométrica. Por fim, sugere-se para pesquisas futuras o levantamento de dados com maior série temporal e limitada a mais subáreas, que ampliem mais o escopo da pesquisa e a amplitude dos resultados. 


\section{REFERÊNCIAS}

ACEDO, F. J.; CASILlAS, J. C. Current paradigms in the international management field: An author co-citation analysis. International Business Review, v. 14, n. 5, p. 619-639, 2005.

ANTHONY, R. N.; GOVINDARAJAN, V. Sistemas de controle gerencial. 4. ed. São Paulo: Atlas, 2006.

ARAÚJO, C. A. A. Bibliometria: evolução histórica e questões atuais. Em questão, v. 12, n. 1, p. 11-32, 2006.

BARDIN, L. Análise de conteúdo. Lisboa: Edições, v. 70, n. 3, 1991.

BARDIN, L. Análise de conteúdo. São Paulo: Edições Setenta, 2011.

BARKEMA, H. G.; GOMEZ-MEJIA, L. R. Managerial Gompensation and Firm Performance: A General Research Framework. Academy of Management Journal, v. 41, n. 2, p. 135-145, 1998.

BOGAERT, J.; ROUSSEAU, R.; VAN HECKE, Piet. Percolation as a model for informetric distributions: fragment size distribution characterised by Bradford curves. Scientometrics, v. 47, n. 2, p. 195-206, 2000.

BOUWENS, J.; LENT, L. Performance measure properties and the effect of incentive contracts. Journal of Management Accounting Research, v. 18, n. 1, p. 55-75, 2006.

CONYON, M. J. Executive compensation and incentives. The Academy of Management Perspectives, v. 20, n. 1, p. 25-44, 2006.

DEGENHART, L.; MARTINS, D. L. C. C.; HEIN, N. Desempenho EconômicoFinanceiro e Remuneração dos Diretores Executivos das Empresas Brasileiras. Enfoque Reflexão Contábil, v. 36, n. 3, p. 118-135, 2017.

DUTRA, J. S. Gestão de pessoas: modelo, processos, tendências e perspectivas. São Paulo: Atlas, 2002.

EGGHE, L. Zipfian and lotkaian continuous concentration theory. Journal of the American Society for Information Science and Technology, v. 56, n. 9, p. 935-945, 2005.

FORTI, C. A. B.; BARBOZA, F. L. M.; RIBEIRO, K. C. S.; NOGUEIRA, S. G. O Impacto do Incentivo aos Funcionários nos Lucros dos Bancos Brasileiros. Enfoque Reflexão Contábil, v. 37, n. 2, p. 51-66, 2018.

GUEDES, V. LS.; BORSCHIVER, S. Bibliometria: uma ferramenta estatística para a gestão da informação e do conhecimento, em sistemas de informação, de comunicação e 
de avaliação científica e tecnológica. Encontro Nacional de Ciência da Informação, v. 6 , n. 1 , p. 1-18, 2005.

HANASHIRO, D. M. M.; TEIXEIRA, M. L. M; ZACARELLI, L. M. Gestão do fator humano: uma visão baseada em stakeholders. 2. ed. São Paulo: Saraiva, 2008.

SILVA, H. C. H.; CASAROTTO, E. L.; BENINI, E. G.; BINOTTO, E. Bibliometria em Estudos Organizacionais: O Perfil das Produções em Ecologia das Organizações. Gestão e Sociedade, v. 12, n. 31, p. 2042-2066, 2018.

JENSEN, M.C.; MURPHY, K.J. Performance pay and top-management incentives. The Journal of Political Economy, v. 98, n. 2, p. 225-264, Apr. 1990

MACHADO JUNIOR, C.; SOUZA, M. T. S.; PARISOTTO, I. R. D. S.; PALMISANO, A. As Leis da Bibliometria em Diferentes Bases de Dados Científicos. Revista de Ciências da Administração, v. 18, n. 44, p. 111-123, 2016.

KRAUTER, E. Contribuição do sistema de remuneração de executivos para o desempenho financeiro: um estudo em empresas industriais brasileiras. Tese de Doutorado. Universidade de São Paulo. 2009.

KRAUTER, E. Remuneração de Executivos e Desempenho Financeiro: um Estudo com Empresas Brasileiras. Revista de Educação e Pesquisa em Contabilidade. v. 7, n. 3, art. 3, p. 259-273, jul./set. 2013

LOTKA, A. J. The frequency distribution of scientific productivity. Journal of the Washington Academy of Sciences, v. 16, n. 12, p. 317-323, 1926.

MACIAS-CHAPULA, C. A. O papel da informetria e da cienciometria e sua perspectiva nacional e internacional. Revista Ciência da Informação, Brasilia, DF, v. 27, n. 2, p. 134-140, 1998.

MURPHY, K. J. Corporate performance and managerial remuneration: An empirical analysis. Journal of accounting and economics, v. 7, n. 1-3, p. 11-42, 1985.

MURPHY, K. J. Executive compensation. Handbook of labor economics, v. 3, p. 2485-2563, 1999.

MILKOVICH, G. T.; BOUDREAU, J. W. Administração de recursos humanos. São Paulo: Atlas, 2000.

OLIVA, E. C.; ALBUQUERQUE, L. G. Sistema de remuneração de executivos e conselheiros como suporte à estrutura de governança corporativa. BASE - Revista de Administração e Contabilidade da UNISINOS, v. 4, n. 1, p. 61-73, 2007.

PRITCHARD, A. Statistical bibliography or bibliometrics? Journal of Documentation, [S.1.], v. 25, n. 4, p. 348-349, 1969. 
RIBEIRO, H. C. M.; TAVARES, V. C. M.; COSTA, B. K. Cocriação de Valor: Uma Bibliometria de 2000 a 2014 . Revista Eletrônica de Estratégia \& Negócios, v. 9, n. 1, p. 118-151, 2016.

RODRIGUES, D. G. N. A diversidade no Conselho de Administração e a utilização de sistemas de incentivos. 2014. Tese de Doutorado. Instituto Superior de Economia e Gestão.

SILVA, J. O.; BEUREN, I. M. Evidenciação da remuneração variável dos executivos nas maiores empresas brasileiras listadas na Bovespa. Enfoque: Reflexão Contábil. v. 34, p. 95-124, 2015.

SOUZA, R. F. WEISS, L. A. S., CAVICHIOLI, D., Dal Vesco, D. G Sistemas de Incentivos e Remuneração de Executivos: Uma Análise da Produção Científica Brasileira. In: X Congresso Anpcont. 2016.

VLACHOS, I. P. The effects of human resource practices on firm growth. International Journal of Business Science and Applied Management, v. 4, n. 2, p. 17-34, 2009.

XAVIER, P. R.; SILVA, M. O.; NAKAHARA, J. M. Remuneração variável: quando os resultados falam mais alto. São Paulo: Makron Books, 1999. 